\title{
Fabrication of Solar Air Cooler
}

\author{
Prof.S.S.Pawar ${ }^{1}$,Akshay Chaudhari ${ }^{2}$,Amit Agre ${ }^{3}$, Mohit Temburkar ${ }^{4}$, Rohit Meshram $^{5}$ \\ ${ }^{1}$ Associate Professor, ${ }^{2345}$ UG Students, Radhikataitai Pandav College Of Engineering,Nagpur,India
}

Received on: 20 May, 2021,

Revised on: 24 June, 2021,

Published on: 26 June, 2021

\begin{abstract}
Article presents the results of an experimental investigation carried out to minimize the power consumption of a solar cooler running at various speeds. The experiments have been carried out for a total of three speeds that is low, medium and high. Speed was control by minimizing the input current at multiple levels with the help of resistors. For high speed, unit has connected to couple of resistors in series, whereas for medium speed couples of resistors were connected in parallel and for low speed a single resistor was used. DC motor in traditional coolers got replaced with Permanent Magnet DC motor. PM DC motor is highly efficient since no electrical energy is used or losses incurred for developing or maintaining motor's magnetic field. Its size is more compact and a better dynamic performance can be expected due to higher magnetic flux density in air gap.PM DC motor has an essentially simplified construction and it is maintenance free, in addition cotton was included in cooler setup. Water is made to flow from a higher potential to lower potential making the grass and cotton wet. Even if the potential of water becomes lower, it does not create any hindrance to the function of cooler. Elimination of pump reduces the expenses in addition to lowering the overheads caused while lifting the water.
\end{abstract}

Keywords- Solar panel, Battery, Charging system, cooler body, PM DC Motor, wires.

\section{I- INTRODUCTION}

O ur project "Solar Cooler" is based on the concept of harvesting solar energy. It is easily interpretable from the name of the project that it is based on the solar energy for satisfying its need of power source. The functionality of Solar Cooler is dissimilar as that of the traditional coolers. The solar energy is harvested and stored in a battery. This battery is in turn connected to the solar cooler for the power source. The concept of solar cooler sounds good and economical hence almost every class of our society can bear its expenses. The best part is that, it can be used even in rural areas where there will be no supply of electricity.

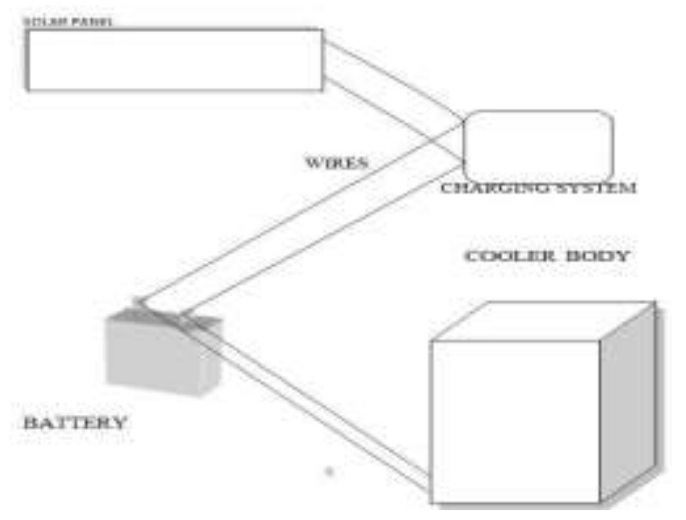

Fig 1- Line diagram of solar water cooler

\section{II- OBJECTIVE}

- Saving power and electricity

- Minimizing season wise servicing

- Varying power consumption at various speeds

- To enable people of those rural areas which do not have electricity supply to have cool air during summer.

- Reduce the maintenance cost by replacing the concept of pump

\section{III- COMPONENT LIST OF A SOLAR COOLER}

- Solar panel 


\section{International Journal of Innovations in Engineering and Science, www.ijies.net}

- Battery

- Charge controller

- PM DC motor

- Centrifugal DC pump

- Cooler body

\section{SOLAR PANEL}

Solar modules use light energy (photons) from the sun to generate electricity through the photovoltaic effect. The majority of modules use wafer-based crystalline silicon cells or thin-film cells based on cadmium telluride or silicon. The structural (load carrying) member of a module can either be the top layer or the back layer. Cells must also be protected from mechanical damage and moisture. Most solar modules are rigid, but semiflexible ones are available, based on thin-film cells.

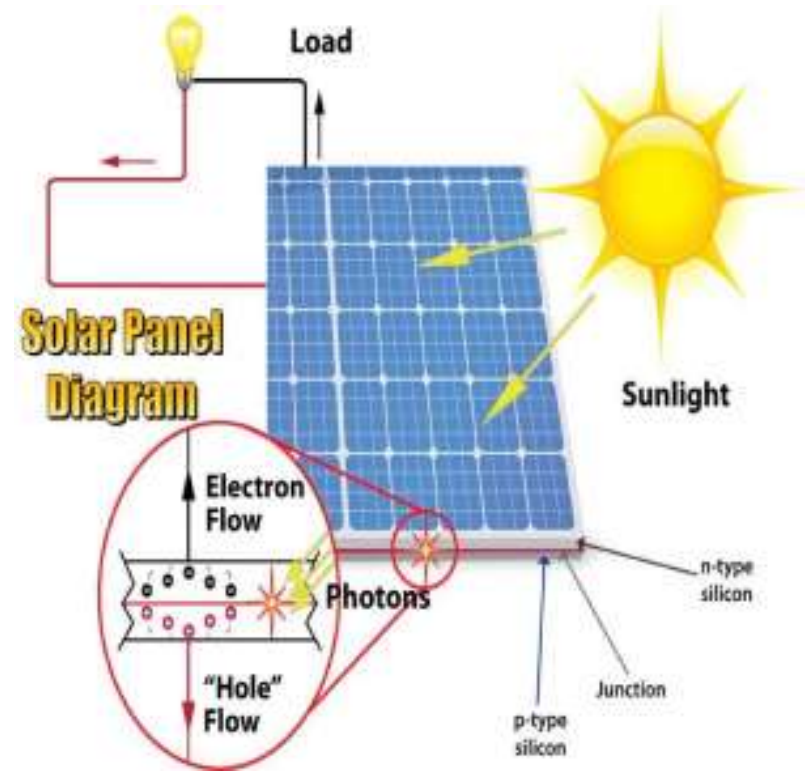

Electrical connections are made in series to achieve a desired output voltage and/or in parallel to provide a desired current capability. The conducting wires that take the current off the modules may contain silver, copper or other non-magnetic conductive transition metals. The cells must be connected electrically to one another and to the rest of the system. Externally, popular terrestrial usage photovoltaic modules use MC3 (older) or MC4 connectors to facilitate easy weatherproof connections to the rest of the system. Bypass diodes may be incorporated or used externally, in case of partial module shading, to maximize the output of module sections still illuminated.

Some recent solar module designs include concentrators in which light is focused by lenses or mirrors onto an array of smaller cells. This enables the use of cells with a high cost per unit area (such as gallium arsenide) in a cost-effective way .

\section{ELECTRICAL CHARACTERISTICS}

Electrical characteristics include nominal power (PMAX, measured in W), open circuit voltage (VOC), short circuit current (ISC, measured in amperes), maximum power voltage (VMPP), maximum power current (IMPP), peak power, $\mathrm{Wp}$, and module efficiency (\%).

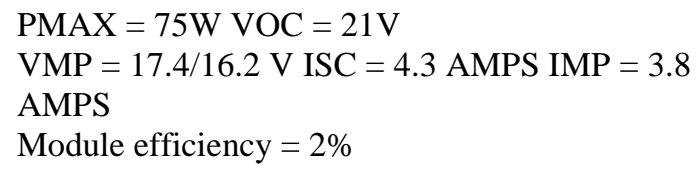

\section{BATTERY (12 V 7.2 AH)}

The common battery (dry cell) is a device that changes chemical energy to electrical energy. Dry cells are widely used in toys, flashlights, portable radios, cameras, hearing aids, and other devices in common use. A battery consists of an outer case made of zinc (the negative electrode), a carbon rod in the center of the cell (the positive electrode), and the space between them is filled with an electrolyte paste. In operation the electrolyte, consisting of ground carbon, Manganese dioxide, Sal ammoniac, and zinc chloride, causes the electrons to flow and produce electricity.

Electricity is the flow of electrons through a circuit or conductive path like a wire .Batteries have three parts, an anode (-), a cathode (+), and the electrolyte. The cathode and anode (the positive and negative sides at either end of a smaller battery) are hooked up to an electrical circuit.

\section{THE “DRY CELL" BATTERY MECHANISM}

The most common type of battery used today is the "dry cell" battery. There are many different types of batteries ranging from the relatively large "flashlight" batteries to the miniaturized versions used for wristwatches or calculators. Although they vary widely in composition and form, they all work on the sample principle. A "drycell" battery is essentially comprised of a metal electrode or graphite rod (elemental carbon) surrounded by a moist electrolyte paste enclosed in a metal cylinder as shown below. 


\section{International Journal of Innovations in Engineering and Science, www.ijies.net}

Dry Cell Battery

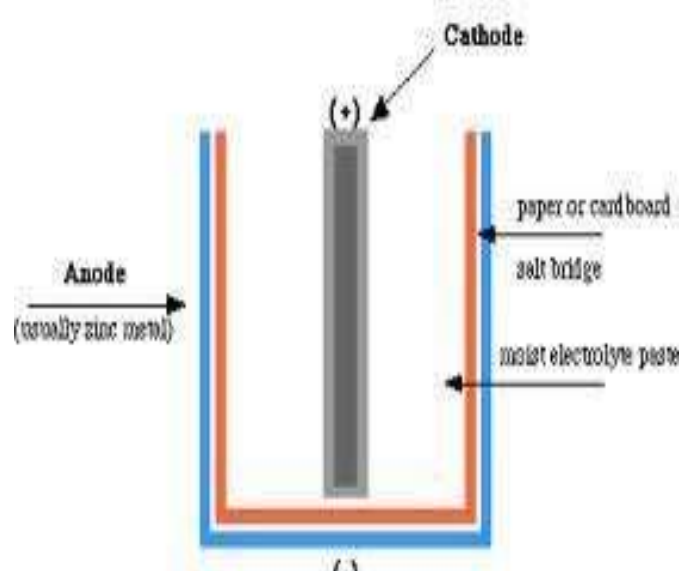

$(-)$

\section{CHARGE CONTROLLER}

A charge controller, charge regulator perform controlled discharges, depending on the battery technology, to protect battery life. The terms "charge controller" or "charge regulator" may refer to either a stand-alone device, or to control circuitry integrated within a battery pack, battery- powered device, or battery recharger.

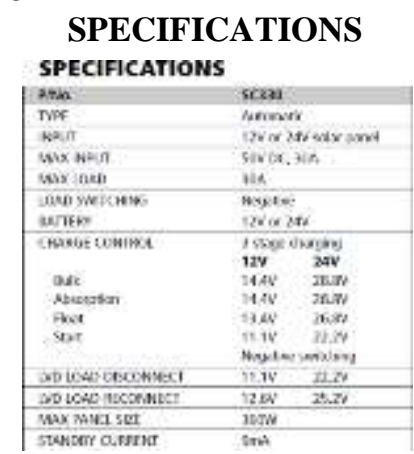

\section{CONNECTIONS}

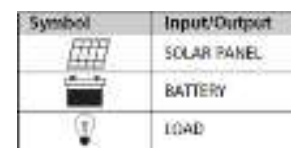

Connections to the solar controller are made via the positive (+) and negative (-) screw terminals at the base of the solar controller. These terminals are illustrated for easy identification as shown in the table to the left.

Note: Ensure connections are made to the correct terminals and polarity +/-.Incorrect installation may cause damage to the battery, solar panel or appliances.

\section{STEP 1 - CONNECT THE BATTERY}

Use suitable cable to connect the battery to the solar controller's BATTERY terminals .It is recommended to install a fuse close to the battery positive $(+)$ terminal. When correctly connected, the SC330 will turn on. The SC330 will automatically detect if the battery is $12 \mathrm{~V}$ or $24 \mathrm{~V}$ and adjust its output accordingly.

\begin{tabular}{|c|c|c|}
\hline \multicolumn{2}{|c|}{ Rexommended Cable } & \multirow[t]{2}{*}{ Recommended Fuse } \\
\hline Lp to $3 m$ & $36 \mathrm{mit}$ & \\
\hline $4.58 \mathrm{~mm}^{\prime}(10 \mathrm{BRS})$ & Notrecommended & $50 A$ \\
\hline
\end{tabular}

\section{STEP 2 - CONNECT THE SOLAR PANEL}

Use suitable cable (refer to solar panel manufacturer's specifications) to connect the solar panel to the solar controller's SOLAR PANEL terminals. Ensure the solar panel is of the same voltage as the battery connected in STEP 1. To check the solar panel is correctly connected scroll through the settings to view the solar panel input voltage. When correctly connected the voltage displayed should be above $3.5 \mathrm{~V}$.

CAUTION: Solar panels always generate energy when exposed to a light source, even

\section{CHARGE CONTROLLER}




\section{International Journal of Innovations in Engineering and Science, www.ijies.net}

if they are disconnected. Accidental 'shorting' of the terminals or wiring can result in sparks, which may cause personal injury, and create a fire hazard. It is recommended that the user cover the front face of the panel(s) with a soft cloth to block incoming light during installation.

\section{STEP 3 - CONNECT THE LOAD/APPLIANCE}

Connect the load or appliance to the solar controller's LOAD terminals

\section{WIRING DIAGRAM}

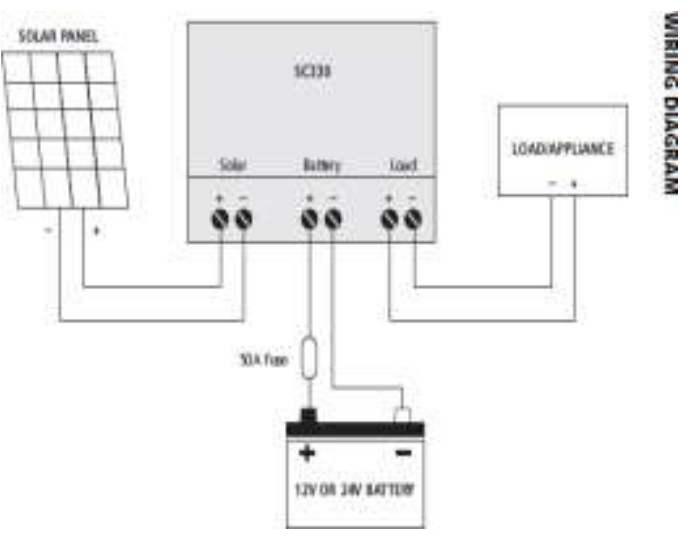

PMDC MOTOR (35W-> $30 \mathrm{~W}$ for fan + $5 \mathrm{~W}$ for pump) INTRODUCTION: Permanent magnet (PM) DC motors were introduced in the 19th century but did not earn widespread acceptance due to the poor quality of magnetic materials (e.g., steel and tungsten steel) that were then available. So, early motor designers turned to electromagnetic field excitation, which became the standard until recently.

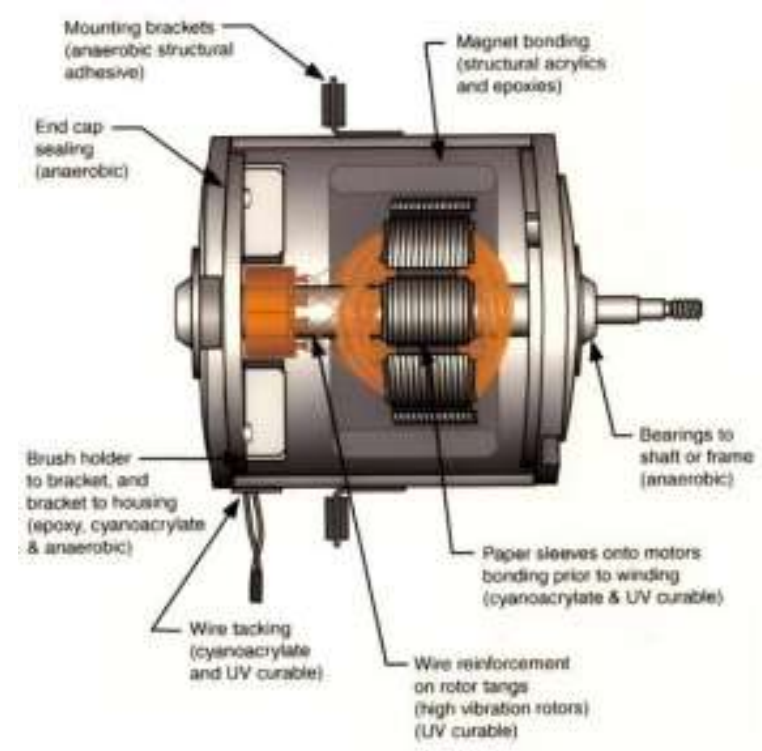

CONSTRUCTION: Permanent magnet DC motors are much more efficient, lighter and compact than comparably sized wound DC motors because the permanent magnets replace the field windings of wound DC motors. PM DC motors are constructed in two broad categories: brushed/commutator and brushless. The PM DC commutator motor uses a rotating armature winding with a stationary field of permanent magnets; a PM DC brushless motor has a reverse construction: a rotating field of permanent magnets and a stationary armature winding that is externally commutated by an electronic control. (Sales of permanent magnet DC commutator motors are steadily decreasing while sales of PM DC brushless motors are increasing due to the absence of brushes and the associated maintenance of the brushes and commutator. Subsequent discussion in this article will refer to the PM DC brushless motor. The field PM magnets have two configurations: surface-mounted or interior-mounted. Surface-mounted magnets are less expensive but are not suited to high speeds. Interiormounted, also called flux concentrating machines, overcome the shortcoming of surfaced mounted machines in terms of air gap flux density, harmonics shielding and, in some cases, structural integrity.

In the 19th century, magnets were made of iron but it was known that 12 alloys of copper, silver and gold made superior magnets. In 1932, Alnico (alloy of AL, $\mathrm{CU}, \mathrm{Fe} \mathrm{NI}$ and $\mathrm{Co}$ ) was developed and reawakened interest in permanent magnet field excitation. In the past 20 years, other magnetic materials have been developed: rare earth magnets, which are samarium-cobalt alloys and are the highest performing magnetic materials. Rare earth magnets are expensive but their price is decreasing. Another material is neodymium-iron-boron alloy, which performs $30 \%$ better than samarium cobalt alloys. The only drawback of neodymium is its poor corrosion resistance; however, protective coatings have been developed to overcome this deficiency.

Ceramic (barium ferrite and strontium ferrite) magnet motors are widely used in the world today. They have much higher coercive forces than alnico and are better able to resist demagnetization.

CHARACTERISTICS: Permanent magnet DC motors have similar characteristics to DC shunt wound motors in terms of torque, speed, reversing and regenerative braking characteristics. However, PM DC motors have starting torque several times that of shunt motors and their speed load characteristics are more linear and predictable. Torque varies a lot with speed, ranging from maximum (stall torque at zero speed) to zero torque at maximum (no load speed). An increase in torque requires a decrease in angular velocity and vice versa.

ADVANTAGES OVER DC MOTOR: 


\section{International Journal of Innovations in Engineering and Science, www.ijies.net}

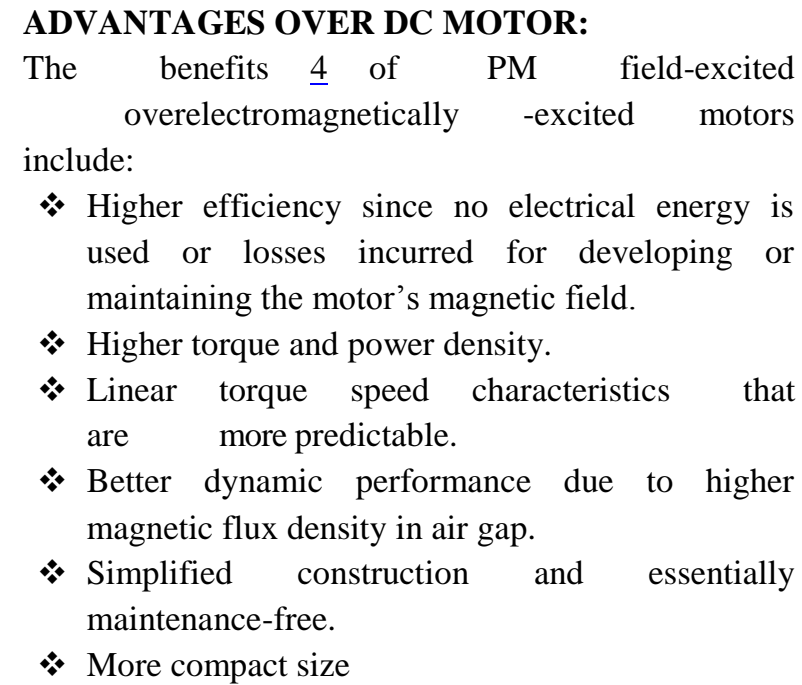

\section{CENTRIFUGAL DC PUMP}

INTRODUCTION: Centrifugal pumps are a sub-class of dynamic axisymmetric work-absorbing turbo machinery. Centrifugal pumps are used to transport fluids by the conversion of rotational kinetic energy to the hydrodynamic energy of the fluid flow. The rotational energy typically comes from an engine or electric motor. The fluid enters the pump impeller along or near to the rotating axis and is accelerated by the impeller, flowing radially outward into a diffuser or volute chamber (casing), from where it exits.Common uses include water, sewage, petroleum and petrochemical pumping. The reverse function of the centrifugal pump is a water turbine converting potential energy of water pressure into mechanical rotational energy.

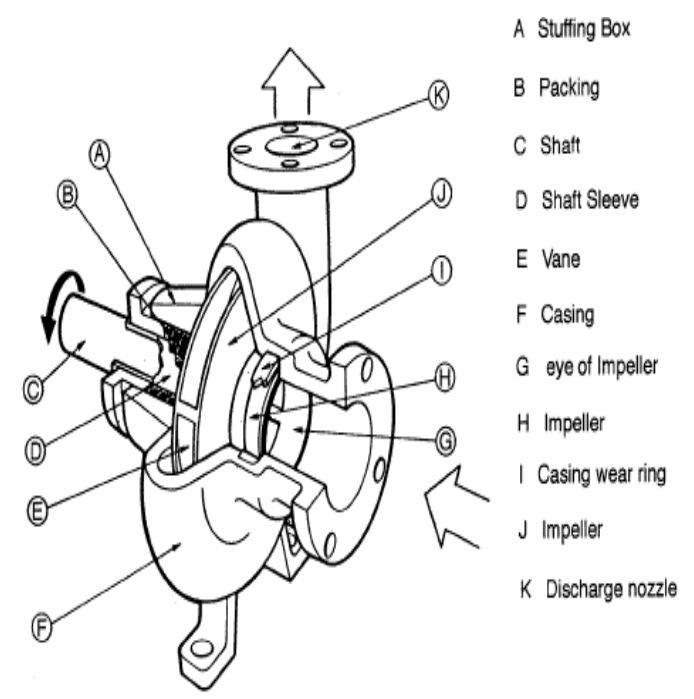

WORKING: Like most pumps, a centrifugal pump converts mechanical energy from a motor to energy of a moving fluid. A portion of the energy goes into kinetic energy of the fluid motion, and some into potential energy, represented by fluid pressure (hydraulic head) or by lifting the fluid, against gravity, to a higher altitude.

The transfer of energy from the mechanical rotation of the impeller to the motion and pressure of the fluid is usually described in terms of centrifugal force, especially in older sources written before the modern concept of centrifugal force as a fictitious force in a rotating reference frame was well articulated. The concept of centrifugal force is not actually required to describe the action of the centrifugal pump. The outlet pressure is a reflection of the pressure that applies the centripetal force that curves the path of the water to move circularly inside the pump. On the other hand, the statement that the "outward force generated within the wheel is to be understood as being produced entirely by the medium of centrifugal force" is best understood in terms of centrifugal force as a fictional force in the frame of reference of the rotating impeller; the actual forces on the water are inward, or centripetal, since that is the direction of force needed to make the water move in circles. This force is supplied by a pressure gradient that is set up by the rotation, where the pressure at the outside, at the wall of the volute, can be taken as a reactive centrifugal force. This was typical of nineteenth and early twentieth century writings, mixing the concepts of centrifugal force in informal descriptions of effects, such as those in the centrifugal pump.

Differing concepts and explanations of how centrifugal pumps work have long engendered controversy and criticism. For example, the American Expert Commission sent to the Vienna Exposition in 1873 issued a report that included observations that "they are misnamed centrifugal, because they do not operate by centrifugal force at all; they operate by pressure the same as a turbine water wheel; when people understand their method of operating we may expect much improvement." John Richards, editor of the San Francisco-based journal Industry, also downplayed the significance of centrifugal force in his essay.

\section{COOLER BODY}

* Cooler body is made up of plastic

* Plastic avoids corrosion and is durable

* Cooler body includes fan, water storage tank and aspen pads

* Aspen pads are soaked in the water making the air cooler 


\section{International Journal of Innovations in Engineering and Science, www.ijies.net}

\section{RESISTORS}

INTRODUCTION TO RESISTOR: A resistor is a passive two-terminal electrical component that implements electrical resistance as a circuit element. Resistors act to reduce current flow, and, at the same time, act to lower voltage levels within circuits. Resistors may have fixed resistances or variable resistances, such as those found in thermistors, varistors, trimmers, photoresistors and potentiometers.

The current through a resistor is in direct proportion to the voltage across the resistor's terminals. This relationship is represented by Ohm's law:

$\mathrm{I}=\{\mathrm{V} \backslash \mathrm{R}\}$

where $\mathrm{I}$ is the current through the conductor in units of amperes, $\mathrm{V}$ is the potential difference measured across the conductor in units of volts, and $\mathrm{R}$ is the resistance of the conductor in units of ohms (symbol: $\Omega$ ).

Series and parallel resistors: In a series configuration, the current through all of the resistors is the same, but the voltage across each resistor will be in proportion to its resistance. The potential difference (voltage) seen across the network is the sum of those voltages, thus the total resistance can be found as the sum of those resistances:

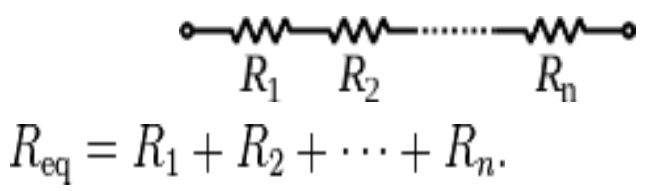

As a special case, the resistance of $N$ resistors connected in series, each of the same resistance $R$, is given by $N R$. Thus, if a $100 \mathrm{~K}$ ohm resistor and a $22 \mathrm{~K}$ ohm resistor are connected in series, their combined resistance will be $122 \mathrm{~K} \mathrm{ohm}$ - they will function in a circuit as though they were a single resistor with a resistance value of $122 \mathrm{~K} \mathrm{ohm}$; three $22 \mathrm{~K}$ ohm resistors $(N=3, R=22 \mathrm{~K})$ will produce a resistance of $3 \times 22 \mathrm{~K}=66 \mathrm{~K}$ ohms.

Resistors in a parallel configuration are each subject to the same potential difference (voltage), however the currents through them add. The conductances of the resistors then add to determine the conductance of the network. Thus the equivalent resistance $\left(R_{e q}\right)$ of then network can be computed:

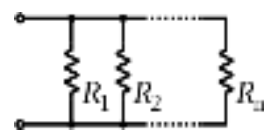

So, for example, a $10 \mathrm{ohm}$ resistor connected in parallel with a $5 \mathrm{ohm}$ resistor and a $15 \mathrm{ohm}$ resistor will produce the inverse of $1 / 10+1 / 5+1 / 15$ ohms of resistance, or
$1 /(.1+.2+.067)=2.725$ ohms. The greater the number of resistors in parallel, the less overall resistance they will collectively generate, and the resistance will never be higher than that of the resistor with the lowest resistance in the group (in the case above, the resistor with the least resistance is the $5 \mathrm{ohm}$ resistor, therefore the combined resistance of all resistors attached to it in parallel will never be greater than $5 \mathrm{ohms}$ ).

The parallel equivalent resistance can be represented in equations by two vertical lines "|l" (as in geometry) as a simplified notation

Occasionally two slashes "//" are used instead of "||", in case the keyboard or font lacks the vertical line symbol. For the case of two resistors in parallel, this can be calculated using:

$\mathrm{R}$ eq $=\mathrm{R} 1 \mathrm{R} 2 /(\mathrm{R} 1+\mathrm{R} 2)$

A resistor network that is a combination of parallel and series connections can be broken up into smaller parts that are either one or the other. For instance,

A diagram of three resistors, two in parallel, which are in series with the other

$\mathrm{R}$ eq $=(\mathrm{R} 1 / / \mathrm{R} 2)+\mathrm{R} 3=\mathrm{R} 1 \mathrm{R} 2 /(\mathrm{R} 1+\mathrm{R} 2)+\mathrm{R} 3$

However, some complex networks of resistors cannot be resolved in this manner, requiring more sophisticated circuit analysis. For instance, consider a cube, each edge of which has been replaced by a resistor. What then is the resistance that would be measured between two opposite vertices? In the case of 12 equivalent resistors, it can be shown that the corner-to-corner resistance is $5 / 6$ of the individual resistance. More generally, the $\mathrm{Y}-\Delta$ transform, or matrix methods can be used to solve such a problem.

One practical application of these relationships is that a non- standard value of resistance can generally be synthesized by connecting a number of standard values in series or parallel. This can also be used to obtain a resistance with a higher power rating than that of the individual resistors used. In the special case of $\mathrm{N}$ identical resistors all connected in series or all connected in parallel, the power rating of the composite resistor is $\mathrm{N}$ times the power rating of the individual resistors.

Power dissipation: At any instant of time, the power $\mathrm{P}$ consumed by a resistor of resistance $R$ (ohms) is calculated as: $P=I^{2} R=I V=\frac{V^{2}}{R}$ where $V($ volts $)$ is the voltage across the resistor and $I$ (amps) is the current flowing through it. The first form is a restatement of Joule's first law. Using Ohm's law, the two other forms can be derived. This power is converted into heat which must be dissipated by the resistor's package.

The total amount of heat energy released over a period of 


\section{International Journal of Innovations in Engineering and Science, www.ijies.net}

time can be determined from the integral of the power over that period of time:

$W=\int_{t_{1}}^{t_{2}} v(t) i(t) d t$

Therefore, one could write the average power dissipated over that particular time period as:

$\bar{P}=\frac{1}{t_{2}-t_{1}} \int_{t_{1}}^{t_{2}} v(t) i(t) d t$.

If the time interval $t_{1}-t_{2}$ is chosen to be one complete cycle of a periodic waveform (or an integer number of cycles), then this result is equal to the long-term average power generated as heat which will be dissipated continuously. With a periodic waveform (such as, but not limited to, a sine wave), then this average over complete cycles (or over the long term) is conveniently given by $\bar{P}=I_{r m s} V_{r m s}=I_{r m s}^{2} R=\frac{V_{r m s}^{2}}{R}$ where $I_{r m s}$ and $V_{r m s}$ are

the root mean square values of the current and voltage. In any case, that heat generated in the resistor must be dissipated before its temperature rises excessively.

Resistors are rated according to their maximum power dissipation. Most discrete resistors in solid-state electronic systems absorb much less than a watt of electrical power and require no attention to their power rating. Such resistors in their discrete form, including most of the packages detailed below, are typically rated as $1 / 10,1 / 8$, or $1 / 4$ watt.

Resistors required to dissipate substantial amounts of power, particularly used in power supplies, power conversion circuits, and power amplifiers, are generally referred to as power resistors; this designation is loosely applied to resistors with power ratings of 1 watt or greater. Power resistors are physically larger and may not use the preferred values, color codes, and external packages described below.

If the average power dissipated by a resistor is more than its power rating, damage to the resistor may occur, permanently altering its resistance; this is distinct from the reversible change in resistance due to its temperature coefficient when it warms. Excessive power dissipation may raise the temperature of the resistor to a point where it can burn the circuit board or adjacent components, or even cause a fire. There are flameproof resistors that fail (open circuit) before they overheat dangerously.

Since poor air circulation, high altitude, or high operating temperatures may occur, resistors may be specified with higher rated dissipation than will be experienced in service.

Some types and ratings of resistors may also have a maximum voltage rating; this may limit available power dissipation for higher resistance values.

POWER CONSUMPTION AT VARIOUS SPEEDS]
-Speed control can be carried out by introducing resistors between the input and the motor

-The speed can be varied by varying the input current by connecting the resistors in different ways.

\section{POWER CONSUMTION AT HIGH SPEED (330 RPM):}

-The incoming voltage is constant at $12 \mathrm{v}$

-2 resistors of resistances $1 \mathrm{ohm}$ and $1 \mathrm{ohm}$ are connected in seies

-Equivalent resistance $\mathrm{R}=\mathrm{R} 1+\mathrm{R} 2=>1+1=2 \mathrm{Ohms}$

-Value of current obtained from ammeter $=2.58 \mathrm{amps}$

-Power $\mathrm{P}=\mathrm{V} * \mathrm{I}=>2.58 * 12=30.96 \mathrm{~W}$

\section{POWER CONSUMTION AT MEDIUM SPEED (250 RPM):}

-The incoming voltage is constant at $12 \mathrm{v}$

-2 resistors of resistances $5 \mathrm{ohms}$ and $10 \mathrm{ohm}$ are connected in parallel

-Equivalent resistance $\mathrm{R}=\mathrm{R} 1 * \mathrm{R} 2 /(\mathrm{R} 1+\mathrm{R} 2)=>10 * 5 /$ $(10+5)=3.3 \mathrm{Ohms}$

-Value of current obtained from ammeter $=1.96 \mathrm{amps}$

-Power $\mathrm{P}=\mathrm{V} * \mathrm{I}=>1.96 * 12=23.52 \mathrm{~W}$

POWER CONSUMTION AT LOW SPEED (204

RPM):

-The incoming voltage is constant at $12 \mathrm{v}$

-A single resistor of resistance $5 \mathrm{ohms}$ is used

-Equivalent resistance $\mathrm{R}=5 \mathrm{ohms}$

-Value of current obtained from ammeter $=1.60 \mathrm{amps}$

-Power $\mathrm{P}=\mathrm{V} * \mathrm{I}=>1.60 * 12=19.2 \mathrm{~W}$

ADVNATAGES OF USING RESISTORS FOR

\section{SPEED CONTROL:}

-Circuits are less complicated

-Cost is less

-The values obtained are precise.

-Significant decrease in power consumption is observed with decrease in speed.

\section{CIRCUIT FOR POWER CONSUMPTION}

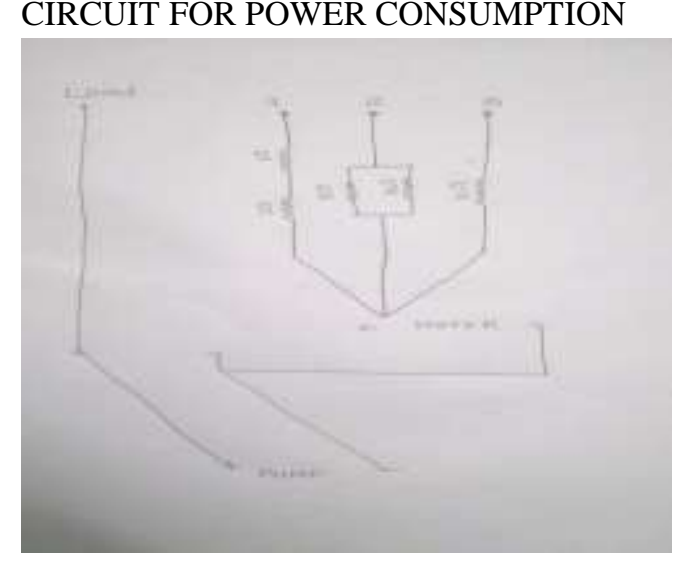




\section{International Journal of Innovations in Engineering and Science, www.ijies.net}

\section{CALCULATION OF PAYBACK}

-Payback is defined as the amount of time in which our product becomes free

-We have replaced the input power source with a solar panel

-The solar panel that we used is of capacity $75 \mathrm{Pw}$

-Cost per watt $=$ Rs 65 . So, the total cost of solar panel is Rs 4850

-1000 watts= 1 unit of power

-The amount charged for 1 unit of power is Rs 6

-For a panel of 75w capacity, 1 unit is charged for an usage of 13.3 hours (since 1000/75=13.3)

-After using the cooler for 1075 days at an average usage of 10 hours per day, -we can expect a return of investment.

-So, the payback period is approximately 2 years 343 days.

\section{COST EFFECTIVENESS BY ELIMINATION OF PUMP}

Earlier in the traditional cooler, pump was used to lift the water up but in our concept of solar cooler the water flows down from the higher potential to downwards making the cotton and cooler grass wet. Thus this wet grass and cotton makes the air cool; even if the potential of water get lowers it does not create any kind of hindrance in the smooth working of the solar cooler.

Cotton works on the principle of capillary tube (Meniscus height).

\section{Height of a meniscus}

The height $\mathrm{h}$ of a liquid column is given by:

$$
h=\frac{2 \gamma \cos \theta}{\rho g r},
$$

where is the liquid-air surface tension (force/unit length), $\theta$ is the contact angle, $\rho$ is the density of liquid (mass/volume), g is local gravitational field strength (force/unit mass), and $\mathrm{r}$ is radius of tube (length).

For a water-filled glass tube in air at standard laboratory conditions, $\gamma=0.0728 \mathrm{~N} / \mathrm{m}$ at $20^{\circ} \mathrm{C}, \theta=20^{\circ}(0.35 \mathrm{rad}), \rho$ is $1000 \mathrm{~kg} / \mathrm{m} 3$, and $\mathrm{g}=9.8 \mathrm{~m} / \mathrm{s} 2$. For these values, the height of the water column is

$h \approx \frac{1.4 \times 10^{-5}}{r} \mathrm{~m}$.

Thus for a $4 \mathrm{~m}(13 \mathrm{ft})$ diameter tube (radius $2 \mathrm{~m}(6.6 \mathrm{ft})$ ), the water would rise an unnoticeable $0.007 \mathrm{~mm}(0.00028$ in). However, for a $4 \mathrm{~cm}$ (1.6 in) diameter tube (radius 2 $\mathrm{cm}(0.79 \mathrm{in})$ ), the water would rise $0.7 \mathrm{~mm}(0.028 \mathrm{in})$, and for a $0.4 \mathrm{~mm}(0.016 \mathrm{in})$ diameter tube (radius 0.2 $\mathrm{mm}(0.0079 \mathrm{in})$ ), the water would rise $70 \mathrm{~mm}$ (2.8 in).

\section{LIMITATIONS}

- The main limitation is that the intensity of solar radiation is weather dependent. On cloudy day, the intensity of radiation is very low which is further affected by the dust, fog and smoke. There for it cannot work properly in cloudy days

- It covers only small area.

- The initial cost of the system is quite high

\section{CONCLUSIONS AND FUTURE SCOPE}

- In traditional coolers a chopper is used for reduction of speed whereas in our cooler we have used resistors which reduce the power consumed along with the variation in speed

- The DC motor has been replaced with the highly efficient PMDC motor, which is maintenance free and simplified in construction.

- Though our intent to replace the concept of pump was unsuccessful, it leaves a lot of scope for future batches to find out a way for eliminating the defects of pump's usage by using an alternative that works in a better way than the cotton.

\section{REFERENCES}

[1] G. K. Dubey. Fundamentals of electrical drives. 2nd ed. Alpha Science International. 2001

[2] Gieras, Jacek F. and Wing, Mitchell. Permanent magnet motor technology: design and applications. Marcel Dekker, Inc. 2002.

[3] C. Elanchezhan, G. Shanmuga Sundar and et al. Computer Aided Manufacturing. 2nd ed. Laxmi Publications 2007.

[4] Sivanagaraju, S and et al. Power Semiconductor Drives. PHI Private Learning Ltd. 2009

[5] Himpel M, Hiebler S, Helm M, Schweigler. Long term test results from a Latent Heat Storage developed for a Solar Heating and Cooling System. EUROSUN, 2010, Austria.

[6] Furukawa T. et al. Study on Characteristic Temperatures of Absorption Heat Pumps. Proc. 20th Japan Heat Transfer Conference; 1983, p. 508-510

[7] Takada S. Absorption Freezer. Japan Freezer Association; 1982

[8] Riesch P. Absorptionswärmetransformator mit hohem Temperaturhub. Forschungsberichte des 
Vol. 6, No. 7, 2021, PP. 21 - 23

International Journal of Innovations in Engineering and Science, www.ijies.net

Deutschen Kälte- und Klimatechnischen Vereins Nr.36. Stuttgart; 1991

[9] Nunez T. Load Generator. Software tool, developed within EU-FP6 project Polysmart. 2010

[10] Storkenmaier F, Harm M, Schweigler C, Ziegler F, Kohlenbach P, Sengewald T. Small-capacity $\mathrm{LiBr}$ Absorption Chiller for Solar Cooling or Waste-Heat driven Cooling. Proc. of the 30th International Congress of Refrigeration, 2003, Washington, USA

[11] Hiebler S, Mehling H, Helm M, Schweigler C.Latent Heat Storage with melting temperature $29{ }^{\circ} \mathrm{C}$ supporting a Solar Heating and Cooling system. Effstock, 2009, Stockholm, Sweden

[12] Helm M, Hagel K, Hiebler S, Schweigler C. Solar heating and cooling with absorption chiller and latent heat storage. Thermally driven heat pumps for heating and cooling, Universitätsverlag der TU Berlin, ISBN (online) 978-3-7983- 2596-8, 2013. p.139-149

[13] 13. M.Rajesh et al. (2018). Fabrication of Solar Air Cooler, $J$ Advancement in Engineering and Technology, V6I3.01. DOI: 10.5281/zenodo.1250080. 